Article

\title{
Bird Pollinator Visitation is Equivalent in Island and Plantation Planting Designs in Tropical Forest Restoration Sites
}

\author{
Catherine A. Lindell ${ }^{1,2, *}$ and Ginger M. Thurston ${ }^{3}$
}

1 Zoology Department, Michigan State University, 288 Farm Ln. Rm. 203, East Lansing, MI 48824, USA

2 Center for Global Change and Earth Observations, Michigan State University, 1405 S. Harrison Rd.Rm. 218, East Lansing, MI 48823, USA

3 Plant Biology Department, Michigan State University, 612 Wilson Rd. Rm. 166, East Lansing MI 48824, USA; E-Mail: thurst29@msu.edu

* Author to whom correspondence should be addressed; E-Mail: lindellc@msu.edu; Tel.: +1-517-884-1241; Fax: +1-517-353-2932.

Received: 20 January 2013; in revised form: 2 February 2013 / Accepted: 13 February 2013 / Published: 19 March 2013

\begin{abstract}
Active restoration is one strategy to reverse tropical forest loss. Given the dynamic nature of climates, human populations, and other ecosystem components, the past practice of using historical reference sites as restoration targets is unlikely to result in selfsustaining ecosystems. Restoring sustainable ecological processes like pollination is a more feasible goal. We investigated how flower cover, planting design, and landscape forest cover influenced bird pollinator visits to Inga edulis trees in young restoration sites in Costa Rica. I. edulis trees were located in island plantings, where seedlings had been planted in patches, or in plantation plantings, where seedlings were planted to cover the restoration area. Sites were located in landscapes with scant (10-21\%) or moderate (35-76\%) forest cover. Trees with greater flower cover received more visits from pollinating birds; neither planting design nor landscape forest cover influenced the number of pollinator visits. Resident hummingbirds and a migratory bird species were the most frequent bird pollinators. Pollination in the early years following planting may not be as affected by details of restoration design as other ecological processes like seed dispersal. Future work to assess the quality of various pollinator species will be important in assessing this idea.
\end{abstract}


Keywords: birds; Costa Rica; ecosystem service; hummingbird; Neotropical migrant; pollination

\section{Introduction}

During the last ten years, global primary forest extent has declined by approximately 0.4 percent annually in large part because of conversion to agriculture [1]. Central and South America, regions with large tropical forest areas, lost nearly 4 million hectares of forest per year from 2005 through 2010 [2]. Among the many benefits provided by tropical forests are maintenance of soil fertility [3], habitat for biodiversity [4], and carbon storage with associated reduction of carbon emissions [5].

Anthropogenic restoration is one strategy to reverse tropical forest loss [6] and will more profitably focus on the restoration of ecosystem processes rather than the restoration of particular assemblages of plants and animals. Given the dynamic nature of soils, climates, human populations, and other ecosystem components, the past practice of using historical reference sites as targets is unlikely to result in self-sustaining ecosystems, or even be doable in many cases [7].

One potentially important facet of restoration design is planting arrangement. Island planting, or applied nucleation [8], involves planting small patches or islands to mimic natural successional processes. In contrast, plantation-style plantings result in an area covered with seedlings. If island planting facilitates restoration equally as well as plantation-style planting, it would be preferred because of lower costs [9]. Our previous work in southern Costa Rica has shown that plantation-style plantings are used more extensively by both insectivorous and frugivorous birds than island plantings, with potential consequences for the ecological processes of arthropod reduction and seed dispersal [10,11].

Pollination is another important ecological process with consequences for plant reproductive success, and, potentially, restoration rates and trajectories [12]. However, studies of pollination within a restoration context have been limited to date $[13,14]$. Animal pollination is particularly important in the tropics; $94 \%$ of tropical plant species are pollinated by animals [15] with birds being a particularly important group of pollinators [16]. Inadequate pollinator visitation rates may impede plant reproductive success with consequences for restoration [17].

Here we compared pollinator visits to Inga edulis trees located in either island or plantation treatments and within landscapes with varying amounts of forest cover. I. edulis is a successional species that develops an extensive canopy within several years of planting and is used more often by birds than other planted species with slower canopy development [11,18]. I. edulis is self-incompatible and thus cross-pollination is a necessary component of the reproductive cycle. Inga species have brush-like flowers that are pollinated by hummingbirds and some nocturnal species of bats and Lepidoptera [19].

Many bird pollinators are hummingbirds. Pollinator visits and pollination success of some hummingbird-pollinated neotropical plant species are positively affected by patch factors such as increasing conspecific flower density e.g., [20,21]. Thus we expected that increasing flower density within a tree would increase bird pollinator visits. We also expected that $I$. edulis trees in plantations 
would have more visits because of greater abundances of I. edulis trees in plantation treatments compared to island treatments. Although a few other plant species were flowering during the study, their abundance was limited, and I. edulis flowers were a primary source of nectar.

Surrounding land cover characteristics can potentially affect bird use of restoration sites [22] so we also examined landscape forest cover as a potential influence on bird pollinator visits. Several studies have shown that tropical hummingbirds (who we assumed would be the most common pollinators) are less affected by landscape characteristics than other groups such as understory insectivores [23-25]. Amazonian forest hummingbird abundance did not change after forest fragmentation [23]. In addition, a large-scale investigation in the study region revealed no strong relationships between land cover characteristics and hummingbird richness or abundance [25]. Based on these previous studies we anticipated that we would see minimal effects of landscape forest cover on bird pollinator visits. However, hummingbird species may vary in their response to land cover characteristics; one common forest-associated hummingbird species in the study area showed different movement paths in agricultural and forested areas [26]. Thus, we also examined the species composition of the potential pollinator assemblage that visited I. edulis flowers and that of all potential pollinator species in the study sites. Such information could indicate whether I. edulis pollinators were less likely, as a group, to respond to landscape characteristics than the entire potential pollinator set.

\section{Methods}

\subsection{Sites}

Study sites were near the Las Cruces Biological Station, Costa Rica, at $8^{\circ} 47^{\prime} \mathrm{N}, 82^{\circ} 57^{\prime} \mathrm{W}$. In 2004 six sites were planted with four species including Inga edulis Mart. [Fabaceae], which is naturalized to the region. Sites were $1090 \mathrm{~m}$ to $1300 \mathrm{~m}$ in elevation and $>1.2 \mathrm{~km}$ apart. Each site included a plantation treatment where seedlings covered the area, $2500 \mathrm{~m}^{2}$, and an island treatment of the same size where seedlings were planted in six patches, at least $8 \mathrm{~m}$ apart: two of $4 \times 4 \mathrm{~m}$, two of $8 \times 8 \mathrm{~m}$, and two of $12 \times 12 \mathrm{~m}$. Seedlings were $2.8 \mathrm{~m}$ apart. At most sites, treatments were $5 \mathrm{~m}$ apart; in a few cases treatments were separated by tens of meters. Treatments were cleared of non-planted vegetation every few months for 2.5 years. See [27] for additional experimental design details.

I. edulis trees were the fastest growing of the four planted species. In July 2007, the mean height of the $I$. edulis trees in the plantation treatments was $452 \pm 136 \mathrm{~cm}$ (range $=237-594 \mathrm{~cm}, n=6)$ and in the island treatments, $423 \pm 158 \mathrm{~cm}$ (range $=213-588 \mathrm{~cm}, n=6$ ). I. edulis inflorescences comprise axillary flower spikes with each flower having a tubular corolla, 1-1.5 m long, and a large number of conspicuous white stamens that extend $2-4 \mathrm{~cm}$ beyond the corolla tube [28].

\subsection{Observations}

Observations took place from October 2007 through March 2008 at each site every three weeks between 6:00 am and 8:30 am. One Inga in each of the two medium and two large patches within the island treatments, and two Ingas in the plantations were observed with binoculars. If an equivalentsized Inga had survived in a small patch, we conducted observations at these trees, for a total of 6-7 trees per site. The same trees were observed each time observations took place. Observed trees were similar 
in height, canopy cover, and distance to patch edge $(<10 \mathrm{~m})$. During each 20 -minute observation period, the observer, J.A. Rosales, sat $10 \mathrm{~m}$ from the tree and recorded all bird visits and whether visiting individuals foraged at flowers, branches/leaves, and/or extra-floral nectaries. Visits by individuals of the same species were counted separately if at least one minute elapsed between initial sightings of the same species in the tree, with two exceptions. In two cases visits were separated by 42 and 46 seconds. We also considered these to be separate visits. Flower cover of each observed tree was estimated after observations as $0 \%$ cover, $1-5 \%$ cover, $6-25 \%$ cover or $26-75 \%$ cover.

\subsection{Mist Netting}

Permanent mist net lanes were established along trails in the three treatments per site in five sites; one site was excluded from sampling for logistical reasons. Three nets, $12 \mathrm{~m}$ long and $2.6 \mathrm{~m}$ high, were used in each treatment during a morning of sampling. Nets were opened within 30 min of sunrise and kept open for five hours, resulting in 15 hours per treatment and a total of 45 hours of sampling per round per site. Nets were closed during rain or high winds. Sampling took place in 2006-2007 and 2007-2008, during November (late wet season), February (dry season) and April (early wet season) for a total of six sampling rounds per site. Birds were identified to species and banded with either numbered metal bands (resident birds) or U.S. Fish \& Wildlife Service bands (North American migrant birds). We weighed birds, took several morphological measurements, and determined age and sex when possible.

\subsection{Land Cover Measurements}

Land cover analyses were conducted using aerial photographs taken in 1998 (the Terra project) and 2005 (the Carta project) in campaigns sponsored by the Costa Rican government. The majority of the classification was made with the 2005 photos, collected during March and April 2005, at a scale of 1:150,000. For a few sites, photos from 1998 were used to fill in areas with shadows or clouds. The 1998 photos were collected from November 1997 to February 1998 at a scale of 1:40,000. Photos were orthorectified by Dr. David Morales and analyses were conducted with ARCGIS 9.1.

Primary and secondary forest and other non-forest land cover classes were identified and quantified manually using texture characteristics and FAO guidelines [29]. Proportions of each class were calculated for $500 \mathrm{~m}$ buffers constructed around the center of each planting design treatment. Groundtruth data were collected in mid 2007 and 2008 to check the classification of each polygon. When discrepancies were found, the classification was changed. We summed the proportions of the primary and secondary forest classes for each buffer and averaged these values for the treatment buffers per site to arrive at one value. We classified each site as having sparse $(10-21 \%, n=3)$, or moderate $(35-76 \%$, $n=3$ ) landscape forest cover.

\subsection{Treatment of Data and Analyses}

Observational data. All observations that took place at trees within island patches were classified in the island treatment and all observations at trees within plantations were in the plantation treatment. 
The birds observed at $I$. edulis trees were classified as pollinators if they were observed foraging at $I$. edulis flowers at some point during the observations.

We determined whether planting treatment and flower cover were independent using a G-test. Numbers of bird pollinator visits were summed for each tree for each date observed. After preliminary analyses and viewing residual plots, we used a square root transformation of the number of bird pollinator visits as the response variable. We used Proc Glimmix [30] to generate generalized linear models with treatment (island or plantation), flower cover within the focal tree, and landscape forest cover as potential explanatory variables. Proc Glimmix allows mixed models with fixed and random factors. Treatment, flower cover, and landscape forest cover were fixed factors. Because bird responses to treatments within a site could have been correlated, we included site as a random effect, allowing us to estimate the proportion of unexplained variance in our final model due to site. We included a repeated measures factor because sites were sampled multiple times.

In addition to the global model containing planting treatment, flower cover, landscape forest cover, all two-way interactions, and the three-way interaction, we generated a nested subset of models. To determine nested models, the variable with the highest $p$-value was excluded at each step. We compared nested models by calculating differences in log likelihood values and using the chi-square distribution. If the difference in values was significant, the model with more variables was kept because it explained the response variable significantly better than the model with fewer variables [31]. The process resulted in the final model.

We checked residual plots to determine if final model fit was adequate. We tested for significant differences between classes within variables using the Contrast statement which computes an $f$ statistic based on a matrix associated with the fixed and random effects of the model [30].

Mist net data. We considered all hummingbird species and the three non-hummingbird species that were observed at I. edulis flowers as potential pollinators. We classified potential pollinator species as open-country species or woody-associated species based on Stiles and Skutch's A Guide to the Birds of Costa Rica [32]. Species were classified as open-country if they prefer non-forest habitats while woody-associated species typically use woodlands, forests, woody agricultural systems like coffee, and diverse home gardens. None of the potential pollinator species would be considered strict forest specialists [32]. We compared the proportions of visits by open-country and woody-associated pollinators to I. edulis trees to the proportions of these two categories captured in mist nets. We used a test of independence with a G-test for this comparison.

\section{Results and Discussion}

There were 297 observation periods and during 195 of those observation periods, at least one bird was observed at the focal tree with 378 total birds and 52 species observed. Eighteen of the birds observed were unidentifiable to species although all but two of these could be classified to at least a family, e.g., Trochilidae, the hummingbird family.

Nine of the observed species were classified as pollinators because they were observed visiting flowers at least once during the study (Table 1). During 105 of the observation periods, at least one pollinator was observed and a total of 179 pollinator individuals were observed. Six of the pollinator species were hummingbirds. Of the three other bird pollinator species, two were Neotropical migrants 
(species that nest in northern North America and winter in Central and South America), and one was a year-round, tropical resident, Coereba flaveola (Table 1).

Table 1. Birds species classified as pollinators, the proportion of their visits to I. edulis where flowers were visited and the proportion of flower visits per species over all flower visits observed.

\begin{tabular}{|c|c|c|c|c|c|}
\hline $\begin{array}{l}\text { Scientific } \\
\text { Name }\end{array}$ & Common Name & Family & $\begin{array}{c}\text { Number of visits } \\
\text { observed at } \\
\text { I. edulis trees }\end{array}$ & $\begin{array}{c}\text { Number of } \\
\text { visits where } \\
\text { flowers were } \\
\text { visited } \\
\text { (Percent) }\end{array}$ & $\begin{array}{c}\text { Percent all } \\
\text { flower visit } \\
\text { observed } \\
\end{array}$ \\
\hline $\begin{array}{c}\text { Amazilia } \\
\text { tzacatl* }^{*}\end{array}$ & $\begin{array}{l}\text { Rufous-tailed } \\
\text { Hummingbird }\end{array}$ & Trochilidae & 78 & $54(69.2)$ & 53.5 \\
\hline $\begin{array}{l}\text { Oreothlypis } \\
\text { peregrina }\end{array}$ & $\begin{array}{l}\text { Tennessee } \\
\text { Warbler** }\end{array}$ & Parulidae & 45 & $9(20.0)$ & 8.9 \\
\hline $\begin{array}{l}\text { Coereba } \\
\text { flaveola }\end{array}$ & Bananaquit & Thraupidae & 18 & $15(83.3)$ & 14.9 \\
\hline $\begin{array}{l}\text { Amazilia } \\
\text { edward* }\end{array}$ & $\begin{array}{l}\text { Snowy-bellied } \\
\text { Hummingbird }\end{array}$ & Trochilidae & 12 & $10(83.3)$ & 9.9 \\
\hline $\begin{array}{c}\text { Setophaga } \\
\text { fusca }\end{array}$ & $\begin{array}{c}\text { Blackburnian } \\
\text { Warbler** }\end{array}$ & Parulidae & 10 & $3(30.0)$ & 3.0 \\
\hline $\begin{array}{c}\text { Chlorostilbon } \\
\text { assimilis* }\end{array}$ & Garden Emerald & Trochilidae & 7 & $3(42.9)$ & 3.0 \\
\hline $\begin{array}{c}\text { Elvira } \\
\text { chionura* }\end{array}$ & $\begin{array}{c}\text { White-tailed } \\
\text { Emerald }\end{array}$ & Trochilidae & 3 & $2(66.7)$ & 2.0 \\
\hline $\begin{array}{c}\text { Unidentified } \\
\text { hummingbird* }\end{array}$ & & Trochilidae & 3 & $2(66.7)$ & 2.0 \\
\hline $\begin{array}{l}\text { Phaethornis } \\
\text { striigularis* }\end{array}$ & $\begin{array}{c}\text { Stripe-throated } \\
\text { Hermit }\end{array}$ & Trochilidae & 2 & $2(100)$ & 2.0 \\
\hline $\begin{array}{c}\text { Phaethornis } \\
\text { guy* }\end{array}$ & Green Hermit & Trochilidae & 1 & $1(100)$ & 1.0 \\
\hline
\end{tabular}

*Hummingbird species; **Neotropical migrant species.

Species varied in the proportions of visits that included foraging at flowers (Table 1). The most common visitor, the Rufous-tailed Hummingbird, foraged at flowers during 69.2 percent of its visits to I. edulis while the second most common visitor, the Tennessee Warbler, only foraged at flowers during $20 \%$ of its visits.

An observed tree's planting treatment was not associated with its flowering category ( $0 \%$ cover, $1-5 \%$ cover, $6-25 \%$ cover or $26-75 \%$ cover), i.e., observed island trees were distributed in the four flowering categories at the same proportions as the plantation trees $(\mathrm{G}=1.42,3$ d.f., $p<0.5)$. The final model to explain number of pollinator visits included only the explanatory variable flower cover ( $\mathrm{F}=27.55, p<0.0001$, Figure 1); neither planting treatment nor landscape forest cover was a significant influence (visits to island trees $=0.55 \pm 1.00$ per observation period and $0.73 \pm 1.11$ to plantation 
trees). Approximately 5.8\% of the unexplained variance of the final model was explained by site, i.e., there was a limited amount of correspondence among the island and plantation treatments at a site.

Figure 1. Pollinator visits to $I$. edulis trees increased with increasing flower cover. 2007-2008 restoration sites in Costa Rica. Bars with different letters are significantly different at the $p<0.05$ level. Errors bars are standard deviations.

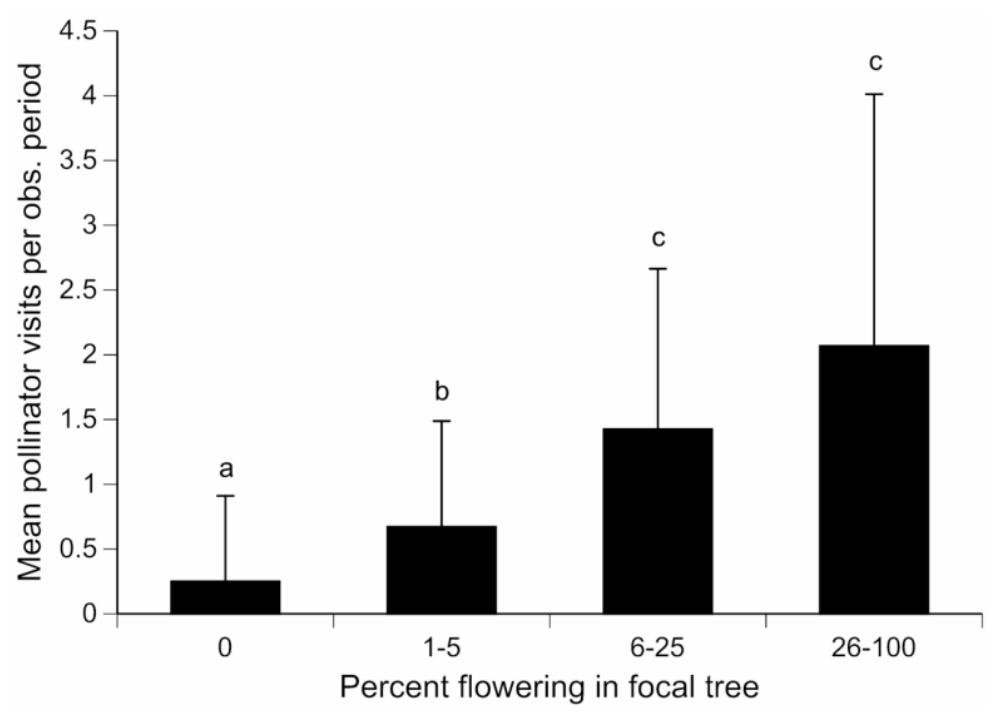

We captured 255 potential pollinators during mist netting in the sites, distributed among fifteen potential pollinator species: twelve hummingbird species and the three non-hummingbird species observed at $I$. edulis flowers. Three of the species (115 individuals) were classified as open-country species and the rest as woody-associated species (140 individuals, Table 2).

Table 2. Potential pollinator species captured during mist netting.

\begin{tabular}{cccc}
\hline English name & Scientific name & $\begin{array}{c}\text { Number of } \\
\text { captures }\end{array}$ & $\begin{array}{c}\text { Open-country or } \\
\text { Woody-associated }\end{array}$ \\
\hline Green Hermit & Phaethornis guy & 23 & $\mathrm{~W}$ \\
Stripe-throated Hermit & Phaethornis striigularis & 7 & $\mathrm{~W}$ \\
Scaly-breasted Hummingbird & Phaeochroa cuvierii & 3 & $\mathrm{~W}$ \\
Violet Sabrewing & Campylopterus hemileucurus & 7 & $\mathrm{~W}$ \\
Garden Emerald & Chlorostilbon assimilis & 16 & $\mathrm{O}$ \\
Violet-crowned Woodnymph & Thalurania colombica & 3 & $\mathrm{~W}$ \\
Blue-throated Goldentail & Hylocharis eliciae & 1 & $\mathrm{~W}$ \\
Charming Hummingbird & Amazilia decora & 6 & $\mathrm{~W}$ \\
Snowy-bellied Hummingbird & Amazilia edward & 9 & $\mathrm{O}$ \\
Rufous-tailed Hummingbird & Amazilia tzacatl & 90 & $\mathrm{O}$ \\
White-tailed Emerald & Elvira chionura & 8 & $\mathrm{~W}$ \\
Green-crowned Brilliant & Heliodoxa jacula & 2 & $\mathrm{~W}$ \\
Bananaquit & Coereba flaveola & 26 & $\mathrm{~W}$ \\
Blackburnian Warbler & Setophaga fusca & 7 & $\mathrm{~W}$ \\
Tennessee Warbler & Oreothlypis peregrina & 47 & $\mathrm{~W}$ \\
\hline
\end{tabular}


The proportion of open-country pollinator species that visited I. edulis trees was significantly higher than the proportion of open-country pollinator species captured in mist nets $(\mathrm{G}=4.38,1$ d.f., $p<0.05)$.

Unlike our previous work indicating that insectivorous and frugivorous birds used plantation-style treatments more than island treatments [10,11,33], planting treatment did not influence numbers of pollinator bird visits to trees in islands compared to plantations. The number of pollinator visits to $I$. edulis was driven primarily by conspecific flower density in focal trees e.g., [20,21]. In addition, pollinator visitation was not influenced by the amount of forest in the landscape. These results may be explained by the fact that most of the pollinator visits were by hummingbirds which often travel widely in search of food. Previous work indicates that hummingbirds as a group show few abundance or species richness effects to landscape characteristics [23-25] although individual species may vary in their responses to land cover patterns [26]. Neotropical migratory birds also follow food supplies in some cases [34,35] and the migrants who visited I. edulis are found in a variety of land cover types in Costa Rica [32]. In addition, the particular assemblage visiting I. edulis had a greater proportion of open-country pollinators and a lower proportion of woody-associated pollinators than were captured in mist nets within the study sites; the composition of the pollinator assemblage was different than might have been expected based on the capture data. This finding indicates that I. edulis may be most attractive to open-country pollinators and suggests the lack of planting treatment and landscape forest cover effects may stem, in part, from the particular combination of I. edulis with its pollinator assemblage.

Our results suggest that pollination, an ecological process with the potential to influence the rate and trajectory of restoration, may occur as readily within island as plantation treatments and within restoration sites with varying amounts of surrounding forest cover. Thus, although plantation-style planting likely has a positive influence on the ecological processes of arthropod reduction by vertebrates and seed dispersal, through positive effects on insectivorous and frugivorous birds [10, 11, 33], similar effects may not occur for pollination, at least at this stage of forest recovery. These findings are in accord with recent work showing that different species interaction networks within ecosystems will not necessarily respond similarly to restoration strategies [36]. Similar research with other plant species used in tropical restoration would help to determine the generality of our results. It would also be valuable to determine pollinator assemblages at $I$. edulis in forest.

Pollinator visitation is an important first step in the process of producing seeds and fruit but further work to document the quality of the different pollinator species would be valuable. For example, Inga sessilis has bat and hawkmoth pollinators, as well as bird pollinators, which varied in their contributions to plant fitness, in Brazil [37]. While bat and hawkmoth pollinators contributed more to fruit production than birds, birds were more consistent pollinators over time and I. sessilis showed adaptations to attract each of the pollinator groups [37]. Additional research on the entire suite of $I$. edulis pollinators, which may also include bats and hawkmoths, would provide a more complete picture of planting design and landscape effects on pollination in this system.

Similarly, even within a group of pollinators, individual species will vary in the quality of pollination services they provide. The bananaquit for example, which regularly visited I. edulis, robs nectar from the flowers of some plant species, coming into contact with the pollen only infrequently, thus providing little pollination [38]. However, the brushy structure of $I$. edulis flowers makes it unlikely that bananaquits can always avoid contact with the pollen-bearing portions of the flower and bananaquits are effective pollinators of other tropical plants [39]. However, future work to quantify 
which pollinator species are most effective with regard to pollen transfer and subsequent seed set would aid in ranking the value of various pollinators. In addition, although I. edulis is a particularly important species in the restoration sites because of its fast growth and the physical structure it provides, the pollination of other species is also important. Future work to determine pollinator visitation rates and pollination success for both planted species and those that have naturally established in the restoration sites would aid in determining the generality of the results for I. edulis.

\section{Conclusions}

Quantifying the success of restoration efforts has become more challenging as restoration ecologists and practitioners have discovered that the practice of using reference sites as targets may not always be feasible or desirable. While a focus on particular species may be warranted in some cases [17], restoring ecological processes will often be a more constructive and attainable goal. This work indicates that pollination in the early years following planting may not be as affected by characteristics of restoration design as other ecological processes like seed dispersal and vertebrate consumption of herbivorous arthropods e.g., [10,11]. Future work to assess whether our results extend to other plantpollinator interactions, which potential pollinator species of I. edulis are the most effective pollinators, and their specific responses to restoration design, will be important in assessing this idea.

\section{Acknowledgments}

We thank Juan Abel Rosales for his critical contributions to this work. We thank the landowners who allowed us access to their property and R. Zahawi, K. Holl, and R. Cole for designing and implementing the restoration sites, with the help of numerous students and volunteers. The Neotropical Migratory Bird Conservation Act Program of the U.S. Fish and Wildlife Service provided funding for some of the work. The Earthwatch Institute and the National Science Foundation (grant DEB 05-15577 to K. Holl and R. Zahawi) funded initial set-up and maintenance of the sites.

\section{Conflict of Interest}

The authors declare no conflict of interest.

\section{References}

1. FAO (Food and Agriculture Organization of the United Nations). Global Forest Resources Assessment 2010. FAO Forestry Paper No. 163. Available online: http://www.fao.org/docrep/ 013/i1757e/i1757e.pdf (accessed on 4 October 2012).

2. FAO (Food and Agriculture Organization of the United Nations). Global Forest Resources Assessment 2010. Global Tables, Trends in extent of Forest 1990-2010. Available online: http://www.fao.org/forestry/fra/fra2010/en/ (accessed 4 October 2012).

3. Tinker, P.B.; Ingram, J.S.I.; Struwe, S. Effects of slash-and-burn agriculture and deforestation on climate change. Agric. Ecosyst. Environ. 1996, 58, 13-22.

4. Gentry, A.H. Tropical Forest Biodiversity: Distributional Patterns and Their Conservational Significance. Oikos 1992, 63, 19-28. 
5. Asner, G.P.; Powell, G.V.N.; Mascaro, J.; Knapp, D.E.; Clark, J.K.; Jacobson, J.; Kennedy Bowdoin, T.; Balaji, A.; Paez-Acosta, G.; Victoria, E.; Secada, L.; Valqui, M.; FlintHughes, R. High-resolution forest carbon stocks and emissions in the Amazon. Proc. Nat. Acad. Sci. USA 2010, 107, 16738-16742.

6. Chazdon, R.L. Beyond deforestation: restoring forests and ecosystem services on degraded lands. Science 2008, 320, 1458-1460.

7. Harris, J.A.; Hobbs, R.J.; Higgs, E.; Aronson, J. Ecological restoration and global climate change. Restoration Ecol. 2006, 14, 170-176.

8. Corbin, J.D.; Holl, K.D. Applied nucleation as a forest restoration strategy. Forest Ecol. Manage. 2012, 265, 37-46.

9. Rey Benayas, J.M.; Bullock, J.M.; Newton, A.C. Creating woodland islets to reconcile ecological restoration, conservation, and agricultural land use. Front. Ecol. Environ. 2008, 6, 329-336.

10. Morrison, E.B.; Lindell, C.A.; Holl, K.D.; Zahawi, R.A. Patch size effects on avian foraging behaviour: implications for tropical forest restoration design. J. Appl. Ecol. 2010, 47, 130-138.

11. Lindell, C.A.; Reid, J.L.; Cole, R.J. Planting design and tree species effects on avian seed dispersers in a tropical forest restoration experiment. Restoration Ecol. 2013, in press.

12. Dixon, K.W. Pollination and restoration. Science 2009, 325, 571-573.

13. Forup, M.L.; Henson, K.W.E.; Craze, P.G.; Memmott, J. The restoration of ecological interactions: plant-pollinator networks on ancient and restored heathlands. J. Appl. Ecol. 2008, 45, 745-752.

14. Lomova, B.; Keith, D.A.; Hochulia, D.F. Pollination and plant reproductive success in restored urban landscapes dominated by a pervasive exotic pollinator. Landscape Urban Plan. 2010, 96, 232-239.

15. Ollerton, J.; Winfree, R.; Tarrant, S. How many flowering plants are pollinated my animals? Oikos 2011, 120, 321-326.

16. Martén-Rodríguez, S.; Almarales-Castro, A.; Fenster, C.B. Evaluation of pollination syndromes in Antillean Gesneriaceae: evidence for bat, hummingbird and generalized flowers. J. Ecol. 2009, 97, 348-359.

17. Kaiser, C.N.; Hansen, D.M.; Müller, C.B. Habitat structure affects reproductive success of the rare endemic tree Syzygium mamillatum (Myrtaceae) in restored and unrestored sites in Mauritius. Biotropica 2008, 40, 86-94.

18. Fink, R.D.; Lindell, C.A.; Morrison, E.B.; Zahawi, R.A.; Holl, K.D. Patch size and tree species influence the number and duration of bird visits in forest restoration plots in southern Costa Rica. Restoration Ecol. 2009, 17, 479-486.

19. Koptur, S. Outcrossing and pollinator limitation of fruit set: breeding systems of Neotropical Inga trees (Fabaceae: Mimosoideae). Evolution 1984, 38, 1130-1143.

20. Feinsinger, P.; Tiebout, H.M., III; Young, B.E. Do tropical bird-pollinated plants exhibit densitydependent interactions? Ecology 1991, 72, 1953-1963.

21. Brody, A.K.; Mitchell, R.J. Effects of experimental manipulation of inflorescence size on pollination and pre-dispersal seed predation in the hummingbird-pollinated plant Ipomopsis aggregate. Oecologia 1997, 110, 89-93.

22. Lindenmayer, D.B.; Knight, E.J.; Crane, M.J.; Montague-Drake, R.; Michael, D.R.; MacGregor, C.I. What makes an effective restoration planting for woodland birds? Biol. Conserv. 2010, 143, 289-301. 
23. Stouffer, P.C.; Bierregaard, R.O. Effects of Forest Fragmentation on Understory Hummingbirds in Amazonian Brazil. Conserv. Biol. 1995, 9, 1085-1094.

24. Pearman, P.B. The scale of community structure: habitat variation and avian guilds in tropical forest understory. Ecol. Monogr. 2002, 72, 19-39.

25. Lindell, C.A.; Chomentowski, W.H.; Zook, J.R.; Kaiser, S.A. Generalizability of neotropical bird abundance and richness models. Animal Conserv. 2006, 9, 445-455.

26. Hadley, A.S.; Betts, M.G. Tropical deforestation alters hummingbird movement patterns. Biol. Lett.-UK 2009, 5, 207-210.

27. Holl, K.D.; Zahawi, R.A.; Cole, R.J.; Ostertag, R.; Cordell, S. Planting seedlings in tree islands versus plantations as a large-scale tropical forest restoration strategy. Restoration Ecol. 2011, 19, 470-479.

28. FAO (Food and Agricultura Organization of the United Nations). 1983. Food and fruit bearing species 3: Examples from Latin America. FAO Forestry Paper. 44/3. Rome. (Available online http://www.fao.org/docrep/016/ap368e/ap368e00.pdf (accessed 18 December 2012).

29. FAO (Food and Agriculture Organization of the United Nations) Appendix 1: Definitions as in Forest Resources Assessment Working Paper 1 and comments. 1998. Available online: http://www.fao.org/docrep/006/ad665e/ad665e06.htm (accessed 5 April 2009).

30. SAS. 2011. Production Glimmix Procedure. Available online: http://support.sas.com/ rnd/app/da/glimmix.html(accessed in March 2011).

31. Stevens, J. Applied Multivariate Statistics for the Social Sciences, 4th ed.; Lawrence Erlbaum Associates: Mahwah, NJ, USA, 2002.

32. Stiles, F.G.; Skutch, A.F. A Guide to the Birds of Costa Rica; Cornell University Press: Ithaca, NY, USA, 1989.

33. Lindell, C.A.; Cole, R.J.; Holl, K.D.; Zahawi, R.A. Migratory bird species in young tropical forest restoration sites: effects of vegetation height, planting design, and season. Bird Conserv. Int. 2012, 22, 94-105.

34. Wunderle, J.M., Jr. Population characteristics of Black-throated Blue Warblers wintering in three sites on Puerto Rico. Auk 1995, 112, 931-946.

35. Brown, D.R.; Sherry, T.W. Alternative strategies of space use and response to resource change in a wintering migrant songbird. Behav. Ecol. 2008, 19, 1314-1325.

36. Pocock, M.J.O.; Evane, D.J.; Memmott, J. The robustness and restoration of a network of ecological networks. Science 2012, 335, 973-977.

37. Amorim, F.W.; Galetto, L.; Sazima, M. Beyond the pollination syndrome: nectar ecology and the role of diurnal and nocturnal pollinators in the reproductive success of Inga sessilis (Fabaceae). Plant Biol. 2012, doi: 10.1111/j.1438-8677.2012.00643.x.

38. Fumero-Cabán, J.J.; Meléndez-Ackerman, E.J. Relative pollination effectiveness of floral visitors of Pitcairnea angustifolia (Bromeliaceae). Am. J. Bot. 2007, 94, 419-424.

39. Caraballo-Ortiz, M.A.; Santiago-Valentín, E. The breeding system and effectiveness of introduced and native pollinators of the endangered tropical tree Goetzea elegans (Solanaceae). J. Poll. Ecol. 2011, 4, 26-33.

(C) 2013 by the authors; licensee MDPI, Basel, Switzerland. This article is an open access article distributed under the terms and conditions of the Creative Commons Attribution license (http://creativecommons.org/licenses/by/3.0/). 